\title{
Modeling the Spatio-Temporal Distribution of the Anopheles Mosquito based on Life History and Surface Water Conditions
}

\author{
Momoyo Kashiwada and Shunji Ohta* \\ Department of Human Behavior and Environment Sciences, Faculty of Human Sciences, Waseda University, 2-579-15 \\ Mikajima, Tokorozawa, Saitama 359-1192, Japan
}

\begin{abstract}
To describe the temporal and geographic distribution of the malaria vector mosquito (Anopheles) at a fine resolution, we modeled the relationship between mosquito life history and climate conditions, focusing on temperaturedependent development of the mosquito. Because Anopheles has aquatic immature life stages, the model was designed to incorporate information on surface moisture conditions suitable for the mosquito. Development was estimated using either air or water temperature, depending on the developmental stage. The model was able to predict seasonal patterns of occurrence of Anopheles at representative sites with reasonable accuracy. Individual emergence of mosquitoes was limited by low water temperatures and/or low moisture conditions at the soil surface in cold or dry seasons. This model was then applied to obtain the geographic distribution of Anopheles occurrence in Monsoon Asia. Spatio-temporal emergence of the Anopheles mosquito was successfully represented using the model and simple climate data. This model can be used to predict the distribution of the mosquito for malaria risk assessments under future scenarios involving climate change and the effects of El Niño-Southern Oscillation events.
\end{abstract}

Keywords: Climatic conditions, life history, malaria, temperature-dependent development, spatio-temporal distribution, water bucket model, water temperature model.

\section{INTRODUCTION}

Because malaria is a mosquito-borne disease, occurrence data for the vector mosquito Anopheles are needed for malaria risk assessments. Martens et al. (1999) assessed the risk of malaria transmission based on the geographic distribution of this mosquito species by country or administrative unit (WHO 1989, Jetten \& Takken 1994). However, the mosquito is not always uniformly distributed within a country, and its range typically crosses national borders. Most entomological studies are unable to incorporate a detailed distribution of the vector mosquito species, although it is the basis for risk assessment of malaria transmission, because the number of observation sites of the Anopheles mosquito is small. Thus, model predictions of Anopheles distribution are necessary to enhance the present data for the distribution of the mosquito.

An integrated, process-based model for estimating the "transmission or epidemic potential" index of the vector population (Martens et al. 1999, van Lieshout et al. 2004) improved on other approaches by taking into account the female mosquito density and associated favorable climate conditions. This index approach is very useful for determining the risk of malaria transmission in a community where mosquito observations have not been conducted. However, climate conditions suitable for the adult female mosquito are not always those that are optimal for the

*Address correspondence to this author at the Department of Human Behavior and Environment Sciences, Faculty of Human Sciences, Waseda University, 2-579-15 Mikajima, Tokorozawa, Saitama 359-1192, Japan; Tel: +81-4-2947-6903; Fax: +81-4-2947-6903; E-mail: shun@waseda.jp Handling Editor: Pierre-Olivier Cheptou immature stages of the mosquito. According to Bayoh \& Lindsay (2003), the optimal temperature range for Anopheles development narrows as the mosquito develops. Furthermore, immature stages of Anopheles live in water such as puddles, pools, or streams; thus, it is necessary to consider the water temperature range suitable for the growth and development of the mosquito.

Recent studies mapping vector species have attempted to explain the geographic distribution of Anopheles and Aedes mosquitoes by analyzing climate variables for the mosquito observation sites using niche-based distribution models (Foley et al. 2008, Medley 2010) or a fuzzy logic model (Craig et al. 1999). These studies have generated highresolution maps of the vectors over large spatial scales using climate data, and the maps are a good indicator of the present distribution of the vector. However, it is difficult for these maps to represent the temporal occurrence of the vectors, because the calculation time-steps in these studies were typically at least a month. However, mosquito development and the life cycle of immature life stages occur at time scales of several days to a few weeks.

On the other hand, ecophysiological approaches have been employed to explain the temporal occurrence of insects by describing their life histories. These models have calculated development with air temperature at each developmental stage of the insect, based on the assumption that the growth of an insect is dependent on the temperature of its habitat (Hopp \& Foley 2001, Depinay et al. 2004). Although such ecophysiological models can generally explain the temporal population dynamics of pest insects at a specific site, they were not able to estimate the geographical distribution of the Anopheles mosquito (Depinay et al. 
2004). To achieve this purpose, the amount and temperature of available aquatic habitats, which vary rapidly, must be incorporated into the model, because, as noted above, immature mosquitoes develop in natural or artificial water bodies. However, the volumes and temperatures of water in the small puddles in which immature mosquitoes live have not been measured over a broad area.

Hopp \& Foley (2001) have expressed the surface water balance and soil moisture content using a simple bucket model. In addition, air temperature has been used in the model in place of water temperature, and this information has been used to obtain the distribution of the Aedes mosquito (Hopp \& Foley 2001). For determining distributions of the mosquito, the simple bucket model is a very effective tool for developing accurate data for the daily water budget at the surface of the soil.

Alternatively, researchers in the field of agricultural meteorology have studied experimental and theoretical relationships between water temperature and meteorological factors (Ohta et al. 1993). More recently, Ohta \& Kimura (2007) successfully improved an energy balance model for open shallow water, estimating the daily mean temperature of paddy water with rice plants using simple meteorological factors. When this model is applied using simple climate variables, water temperature can be estimated with great precision over a broad spatial scale.

Therefore, in the present study, the life history of the Anopheles mosquito is described as a function of climate variables based on an ecophysiological approach, coupled with models of the availability and temperature of surface water. Although a variety of Anopheles species are located at a site, we used the physiological data of some species available from references to consider the broad-scale distribution of the mosquito. The resulting method provides simultaneous spatial and temporal distributions for the Anopheles mosquito at a fine resolution. Here, we present a validation of the model and describe the current distributions of Anopheles in monsoon Asia.

\section{MATERIALS AND METHODS}

\section{Model Description}

The model consists of three parts; the primary part of the model calculates the growth of the mosquito, and two subprocesses of the model determine the moisture conditions of the mosquito habitat and calculate the water temperature. The calculation time-step for all three parts of the model was one day.

\section{Growth Model for the Mosquito}

Numbers ranging from 0 to 4 describe the progression of an egg through the mosquito life cycle to a mature adult (Fig. 1a). Numbers between 0 and 1 were attributed to embryonic development. Larval development was described using numbers between 1 and 2, and pupal development was described using numbers between 2 and 3 . Values exceeding 3 were assigned following the emergence of adults. Numbers exceeding 4 were assigned when adult mosquitoes oviposited eggs. The alternation of generations was counted over a 1-year period $\left(G_{i}\right)$, and the maximum number was described as the maximum number of generations $\left(G_{\max }\right)$ to estimate the frequency of occurrence (Kiritani 2006).

The daily growth of mosquitoes was calculated using the temperature-dependent developmental rate when a water body was available to host the immature mosquito. This value of growth was accumulated at each day until the mature-adult stage when the mosquitoes were capable of laying eggs (Fig. 1b).

The developmental rate was determined by the temperature of the habitat. This study used the water temperature to calculate development of the egg, larval, and pupal stages,

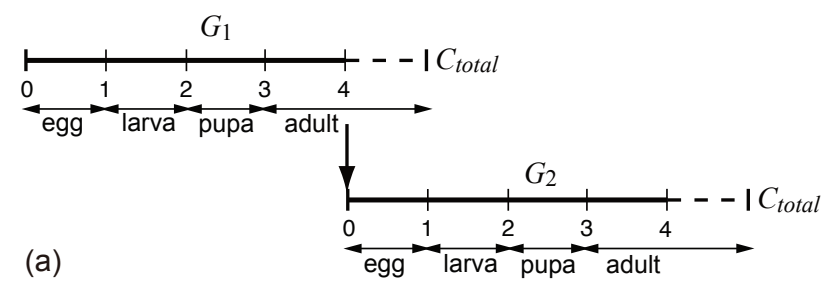

(b)

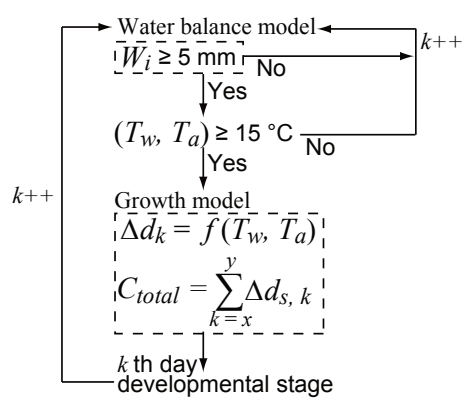

(c)

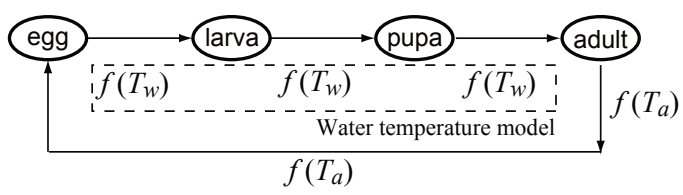

Fig. (1). Model procedures. (a) Calculation of mosquito growth. The developmental process from the hatching of the egg to adult mosquito oviposition was described using numbers 0 to 4 . After developing into the adult mosquito, indicated by 4 , it continues to live as an adult until death. $G_{1}$ corresponds to the $1^{\text {st }}$ generation, and $G_{2}$ corresponds to the $2^{\text {nd }}$ generation. (b) Determination of moisture conditions. The soil moisture content $\left(W_{i}\right)$ at root depth was determined before developing the growth model for the mosquito. The threshold of $W_{i}$ was set to $5 \mathrm{~mm}$ to exclude the emergence of mosquitoes during the dry season from the validation process. The variable $k$ represents the day number, and $k++$ signifies addition of 1 day to $k$. Thus $k++$ can also be illustrated as $k=k+1$. The additional character $s$ represents the developmental stage, which can be egg, larva, pupa, or adult. Additional characters $x$ and $y$ represent the start and end date of the mosquito development, respectively. (c) Relationship between life history and temperatures. Because the three immature stages of the mosquito live in water bodies, the developmental rate was affected by the water temperature $\left(T_{w}\right)$. The developmental rate of the adult mosquito was determined by the air temperature $\left(T_{a}\right)$. 
and the air temperature to calculate the development of the adult mosquito (Fig. 1c). The developmental rate at a specific temperature was calculated using the following formula:

$$
R_{\text {Temp }}=\frac{1}{D_{\text {Temp }}}
$$

where $D_{T e m p}$ is the duration for the completion of each developmental stage (day) at a given constant temperature $\left({ }^{\circ} \mathrm{C}\right) . R_{\text {Temp }}$ is the developmental rate per day at a given temperature $\left({ }^{\circ} \mathrm{C}\right)$, which was defined as the inverse of the $D_{\text {Temp }}$ for each stage. $R_{\text {Temp }}$ ranged from 0 to 1 , with 0 representing no development and the amount of development increasing as the value approached 1 (Lardeux et al. 2008). The development at 1 day (during a given period, $\Delta t_{k}=t_{k}$ $t_{k-1}$ ) could be described as follows:

$$
\Delta d_{k}=R_{\text {Temp }} \times \Delta t_{k}
$$

where $\Delta d_{k}$ is the development at $k$ th day; $k$ is the given value of day; $k-1$ is the previous day of the $k$ th day; $\Delta t_{k}$, is the time unit of development. The value of $\Delta d_{k}$ was accumulated with calendar time in order to determine the amount of development. Usually, cumulative $\Delta d_{k}$ is determined separately in each developmental stage, as the developmental rate is obtained differently. This means that each stage of development-egg, larva, pupa, and adult-is completed when the accumulated development is 1 . In this growth model, the value of $\Delta d_{k}$ for each developmental stage was accumulated continuously as follows to determine the duration of mosquito development in its life history:

$$
\begin{aligned}
C_{\text {total }}=\sum_{k=l}^{m} \Delta d_{\text {egg }, k}+\sum_{k=m+1}^{n} \Delta d_{\text {larva }, k}+\sum_{k=n+1}^{o} \Delta d_{p u p a, k} & \\
& +\sum_{k=o+1}^{q} \Delta d_{\text {adult }, k}
\end{aligned}
$$

where $C_{\text {total }}$ is the cumulative development; $l, m+1, n+1$, and $o+1$, indicate the developmental start day of each developmental stage; $m, n, o$, and $p$ indicate the developmental end day of each developmental stage; and $\Delta d_{\text {egg, } k}, \Delta d_{\text {larva, } k}$, $\Delta d_{\text {pupa, } k}$, and $\Delta d_{\text {adult, } k}$, are the development of egg, larva, pupa, and adult mosquito at the $k$ th day. The value of each $\Delta d_{k}$ ranged from 0 to 1 , hence $C_{\text {total }}$ ranged from 0 to 4 (Fig. 1a).

To deal with the different temperatures on different days, the relationships between $R_{\text {Temp }}$ and temperature were expressed as regression equations in each developmental stage based on the data for $D_{\text {Temp }}$ (Fig. 2). Values for $D_{\text {Temp }}$ were obtained based on the results of laboratory studies and field observations (Mogi \& Okazawa 1996, Bayoh \& Lindsay 2003, Hu et al. 2003, Lardeux et al. 2008). These studies have elucidated the relationship between the temperature threshold and mosquito development. The data are plotted in Fig. (2) for each developmental stage: egg, larva, pupa, and adult. The plots include data for some Anopheles species. The daily developmental rate of the larvae is relatively low because larvae that have 4 instars require a longer

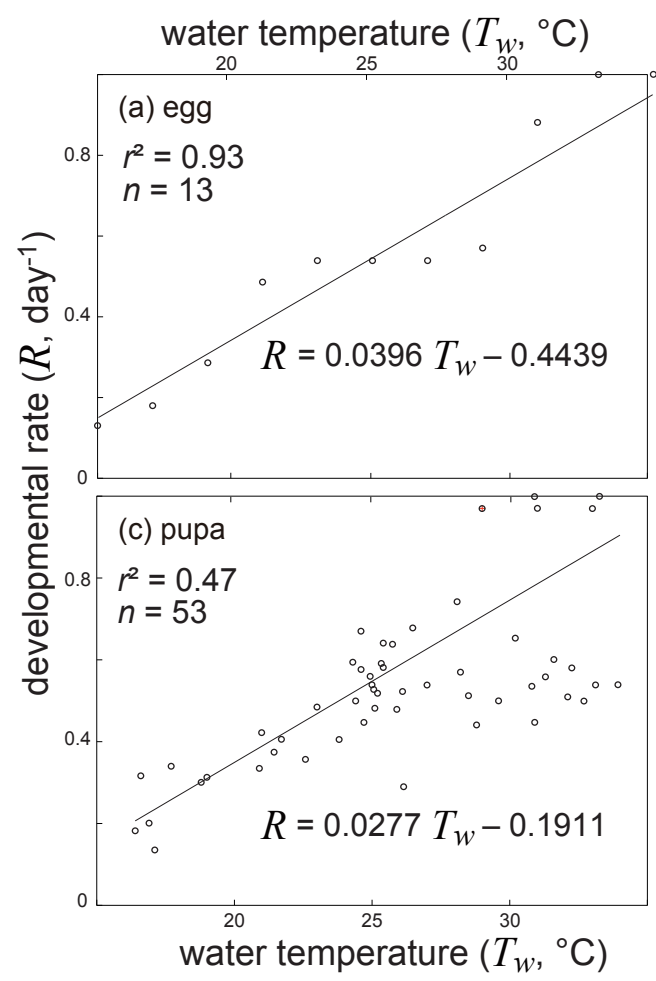

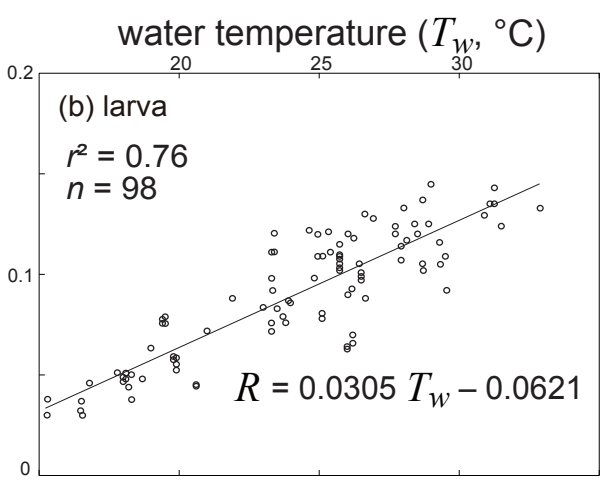

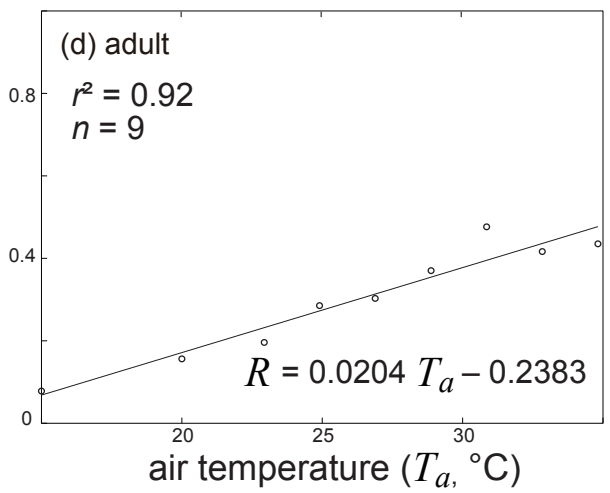

Fig. (2). Dependence of the developmental rate $\left(\mathrm{day}^{-1}\right)$ of the Anopheles mosquito on temperature. The coefficient of determination and regression equation are shown in each panel. The plotted data for each life stage were obtained from the following references: (a) egg stage, A. gambiae (Bayoh \& Lindsay 2003); (b) larval stage, A. sinensis (Mogi \& Okazawa 1996), A. minimus, A. dirus, A. stephensi (Hu et al. 2003), and A. gambiae (Bayoh \& Lindsay 2003); (c) pupal stage, A. sinensis (Mogi \& Okazawa 1996) and A. gambiae (Bayoh \& Lindsay 2003); (d) adult stage, A. pseudopunctipennis (Lardeux et al. 2008). A growth model was conducted when the temperature was in the range $15-39^{\circ} \mathrm{C}$, which was determined as the threshold value of adult mosquito emergence by Bayoh \& Lindsay (2003) and Depinay et al. (2004). 
developmental time than the other stages. It is clear that the developmental rate $\left(\right.$ day $\left.^{-1}\right)$ increases with temperature (Fig. 2). We determined the lower temperature threshold as $15^{\circ} \mathrm{C}$, because, according to the previous experiments, mosquitoes could not develop into adult below this temperature (Bayoh \& Lindsay 2003; Depinay et al. 2004). The plotted data were fitted using the linear least-squares method and the resulting regression equations were used to calculate the daily developmental rate $\left(R_{\text {Temp }}\right)$ using Eq. (1).

\section{Adaptation of the Growth Model to an Ideal Site for the Mosquito}

Immature mosquito development takes place in small water bodies such as puddles or other artificial water containers. To consider the potential distribution of the Anopheles mosquito, the availability of a natural water surface was assumed in this study. Under natural conditions, these would be small pools in marsh or wetland areas with some plant cover. For this study, the Anopheles mosquito was assumed to develop in a small body of water with an area of a few square meters. To exclude areas that were too arid for an immature mosquito to survive, the soil moisture content was taken into account. Soil moisture content at the depth of plant roots was calculated using the water budget approach proposed by Hopp \& Foley (2001) and Tao et al. (2003). Calculation of the soil moisture content on the $i$ th day $\left(W_{i}\right)$ was conducted using the following equation:

$W_{i}=\min \left(W_{i-1}+P_{i}+M_{i}-A E_{i}, W^{*}\right)$

where $W_{i-1}$ is the soil moisture content at the end of the previous day $(i-1), P_{i}$ is the daily precipitation $\left(\mathrm{mm} \mathrm{d}^{-1}\right), M_{i}$ is the daily snow melt on the $i$ th day, $A E_{i}$ is the actual evapotranspiration on the $i$ th day, and $W^{*}$ is the soil moisture holding capacity, which reflects the effects of soil texture, soil organic content, and plant root depth, obtained from Dunne \& Willmott (1996). Tao et al. (2003) determined the value of $A E_{i}$ as a ratio of the available moisture content to the potential evapotranspiration $\left(P E_{i}\right)$ calculated using the FAO Penman-Monteith method (Allen et al. 1998). This method assumes $P E_{i}$ for cropland; coefficients prior to cultivation were derived from Allen et al. (1998), because an immature mosquito was assumed to live in a small pool in natural areas such as wetlands or marshes. Calculation of $P E_{i}$ requires data for net radiation, air temperature, air humidity, and wind speed. In the present study, net radiation was calculated using an energy balance equation (Ohta et al. 1993), and wind speed was assumed to be constant at $2 \mathrm{~ms}^{-1}$, in accordance with Allen et al. (1998).

\section{Temperature of the Water Body in which the Mosquito Lives}

The temperature of the water body in which the Anopheles mosquito lives directly affects immature mosquito development. Unfortunately, water temperature has not been measured with fine resolution spatially and temporally, as has been done for both air temperature and precipitation. According to Ohta \& Kimura (2007), the water temperature in temperate regions is lower than the air temperature by $2-4^{\circ} \mathrm{C}$ during the period of insufficient net radiation in the winter. Conversely, the water temperature is higher than the air temperature by $1-2{ }^{\circ} \mathrm{C}$ in the spring. Because these seasonal changes in the differences between air and water temperatures are complex, it cannot be assumed that air temperature and water temperature are the same.

Ohta et al. (1993) evaluated the temperature of ponded shallow water with a water depth of $5-10 \mathrm{~cm}$ without percolation or heat flux due to irrigation, and modeled water temperature as initially affected by energy partitioning between air, water, and soil. This modeled condition is nearly the same as the ideal habitat for the immature stages of the mosquito considered in this study. Therefore, water temperature was estimated using a simple energy balance model, as well as the methods developed by Ohta et al. (1993). Calculation of the water temperature requires basic climate factors, including air temperature, solar radiation, cloud cover, and vapor pressure.

\section{Data Used for Calculation of the Temporal and Spatial Distributions}

\section{Climate Data Used for Application of the Model}

Data for the Asian region $\left(70-150^{\circ} \mathrm{E}, 10^{\circ} \mathrm{S}-50^{\circ} \mathrm{N}\right)$ were used in the model (Fig. 3). All climate data had a spatial resolution of $0.5^{\circ}$ lat $\times 0.5^{\circ}$ long (about $50 \mathrm{~km}^{2}$, total number of grid cells $=19481)$, interpolated or extrapolated climatologically or geologically if necessary. The CRU Global Climate Dataset, available through the IPCC Data Distribution Center (New et al. 1999) was used for the model calculations. Monthly data for air temperature, precipitation, vapor pressure, solar radiation, and cloud cover were included in the dataset for 1961-1990 climate normals. If daily data were not available for the model, monthly values were converted to daily data using cubic spline or linear interpolations, ensuring consistency of the daily values with monthly means or totals. Although it is desirable to obtain daily climate data for model calculation, these interpolation methods enabled us to perform the calculation when only the monthly values of air temperature, precipitation, vapor pressure, solar radiation, and cloud cover were available.

\section{Mosquito Observation Data Used for Validation of the Model}

For validation of the model, we gathered observation data for the Anopheles mosquito from the literature (Fig. 3). Observation data for the entire year were available only for Yunnan Province in China (Ono 1992), Ishigaki Island in Japan (Toma et al. 2002), Kyonggi-do in South Korea (Lee et al. 2002), Cheolwon and Yeoncheon Counties in South Korea (Yeom et al. 2005), Chiang Mai in Thailand (Overgaard et al. 2002), Kheda District in India (Konradsen et al. 1998), and Assam in India (Dev 1996).

Yunnan (a rural community at $21.75^{\circ} \mathrm{N}, 100.75^{\circ} \mathrm{E}$, altitude $500 \mathrm{~m}$ ) is located in southwest China, bordering three malaria-endemic countries, Myanmar, Laos, and Vietnam. Ishigaki Island $\left(24.30^{\circ} \mathrm{N}, 124.10^{\circ} \mathrm{E}\right.$, altitude $\left.6 \mathrm{~m}\right)$ is located approximately $700 \mathrm{~km}$ south of Okinawa Island. Malaria was endemic on Ishigaki Island and the other islands of Yaeyama, Ryukyu Archipelago until 1962. Kyonggi-do $\left(37.50^{\circ} \mathrm{N}, 127.25^{\circ} \mathrm{E}\right.$, altitude $\left.85 \mathrm{~m}\right)$ is a northern county bordering North Korea. These border regions suffer from infiltration of infected mosquitoes from North Korea from June to September. Cheolwon $\left(38.14^{\circ} \mathrm{N}, 127.31^{\circ} \mathrm{E}\right.$, altitude $0 \mathrm{~m})$ and Yeoncheon $\left(38.09^{\circ} \mathrm{N}, 127.07^{\circ} \mathrm{E}\right.$, altitude $\left.0 \mathrm{~m}\right)$ are 


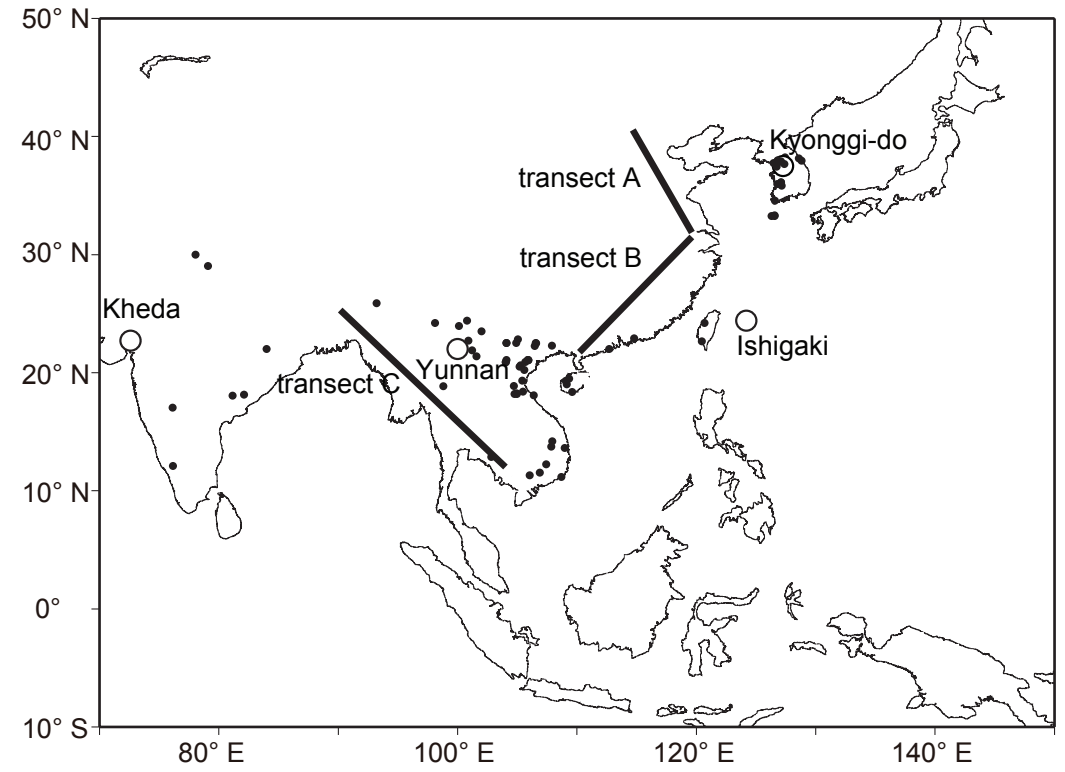

Fig. (3). Anopheles mosquito observation sites and three transects for analysis. Small closed circles indicate observation sites of the Anopheles species reported in published data (Dev 1996, Chen et al. 2002, Overgaard et al. 2002, Singh et al. 2004, Yeom et al. 2005, Chen et al. 2006, Rueda et al. 2006). Open circles are representative observation sites (Fig. 5) with data on the seasonal variation of the population density of Anopheles species (Ono 1992, Konradsen et al. 1998, Lee et al. 2002, Toma et al. 2002). To analyze the occurrence of Anopheles mosquito simulated by the model with variations in temperature and moisture condition, both the output of the model and climate data on transects A, B, and C was extracted. These transects were set along the seashore, as mosquitoes are rarely found in inland areas. Transects A and $\mathrm{B}$ were set to examine the relationship between temperature condition and mosquito emergence. Transect $\mathrm{C}$ was set to examine the relationship between moisture condition and mosquito emergence.

also northern border counties near North Korea. Chiang Mai Province is located in northern Thailand $\left(19.13^{\circ} \mathrm{N}, 98.86^{\circ} \mathrm{E}\right.$, altitude $400-600 \mathrm{~m}$ ). The valley is covered with paddy fields, agricultural crops, and fruit orchards, and is surrounded by hills with tropical deciduous forests. Kheda District $\left(22.74^{\circ}\right.$ $\mathrm{N}, 72.68^{\circ} \mathrm{E}$, altitude $0 \mathrm{~m}$ ) is a semi-arid area in the state of Gujarat, India. There has been occurrence of Anopheles populations in the cropping season. Assam $\left(26.11^{\circ} \mathrm{N}, 91.98^{\circ}\right.$ $\mathrm{E}$, altitude $0-150 \mathrm{~m}$ ) is predominantly tribal, low-lying, and prone to flooding, and most of the villages are located in the foothills.

\section{Validation of the Model}

For validation of the model, climate data measured at the same time as the mosquito observations (Ono 1992, Toma et al. 2002) were also used for the validation. If observation data were not obtained, climate data from the CRU Global Climate Dataset, available through the IPCC Data Distribution Center (New et al. 1999) were used. The $C_{\text {total }}$ was calculated using the local climate data as mentioned above. If the value of the $C_{\text {total }}$ calculated from $k$ th day was over 3, we defined the $k$ th day as the day of mosquito emergence. This calculation was then conducted in all cases where the developmental start day was from the $1^{\text {st }}-365^{\text {th }}$ day of year. As the mosquito could have emerged over a different year, we performed the calculation over 2 years. The first date of mosquito emergence was defined as the mosquito appearance date and the end date of mosquito emergence was defined as the mosquito disappearance date.

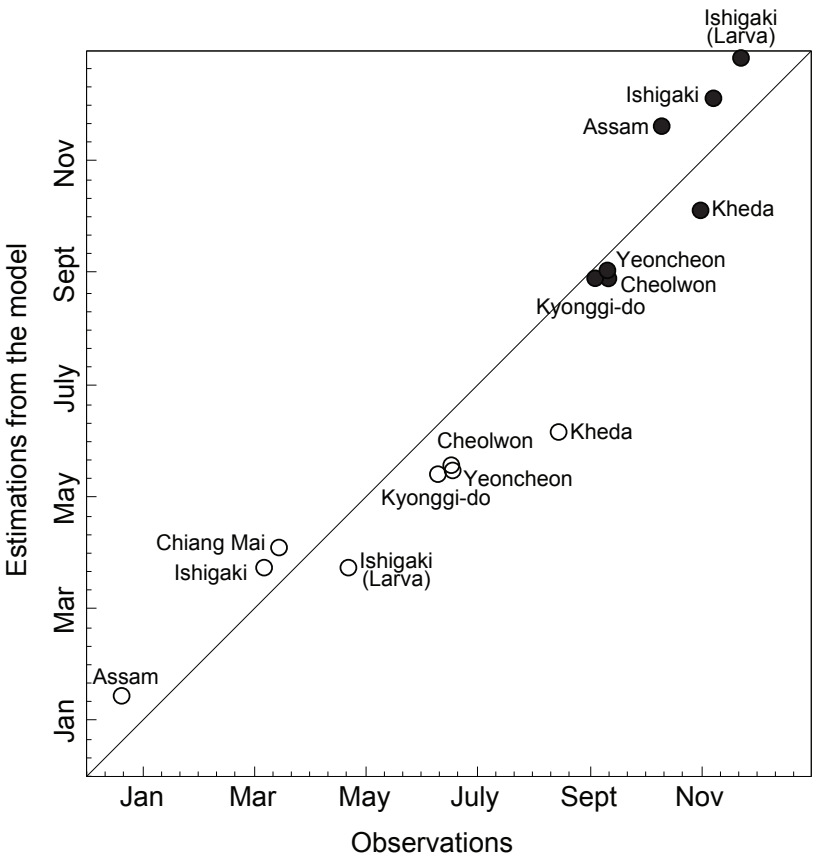

Fig. (4). Relationships between the observed and modeled values for the dates of appearance and disappearance of the Anopheles mosquito. Open circles are emergence dates and closed circles are disappearance dates. Data for Ishigaki Island in Japan; Cheolwon, Yeoncheon, and Kyonggi-do in South Korea; Kheda and Assam in India; and Chiang Mai Province in Thailand were plotted. $P<0.01$, RMSE $=39 \mathrm{~d}$ for the start date. $P<0.01, \mathrm{RMSE}=27 \mathrm{~d}$ for the end date. 
The predicted emergence or disappearance dates obtained from the model were plotted against the observed data (Fig. 4). We calculated the root mean square errors (RMSE) between the observed and modeled values for these dates. Although the RMSE values were approximately 1 month, the values are acceptable for simulation of the potential mosquito distribution, because the timescales of the mosquito occurrence observations were typically monthly, according to the references (Dev 1996; Konradsen et al. 1998; Overgaard et al. 2002).

\section{RESULTS}

\section{Patterns of Temporal Mosquito Emergence}

To validate the model circumstantially, the cumulative development $\left(C_{\text {total }}\right)$ was calculated daily for 4 representative observation sites in various climates (Fig. 5, center panel). The daily value of $C_{\text {total }}$ indicated the stage to which the mosquito can develop, and we defined this value as the maximum developmental stage. The model outputs were compared with the seasonal population densities observed at each site (Fig. 5, lower panel). The results for water conditions are also shown in Fig. (5) (upper panel).

In Yunnan, the water temperature was $<15^{\circ} \mathrm{C}$, the lower temperature threshold, from November to January. The soil moisture content was highest in August and then decreased gradually. However, the soil moisture content was sufficient for mosquito development over the year. Except for November-January, the maximum developmental stage reached was the adult stage. According to field observations (Ono 1992), larvae appeared during all observation periods, and adult emergence was limited from November to February.

In Ishigaki, the water temperature was $>15^{\circ} \mathrm{C}$ and the soil moisture content was $>10 \mathrm{~mm}$ over the course of the year. The maximum developmental stage was $\sim 0-2$ from December to March, and 4 during the rest of the year. According to field observations (Toma et al. 2002), the population density of adult mosquitoes peaked in May, and was low from June to November. From December to March, the adult mosquito density was nearly 0 . The immature-stage mosquito appeared throughout the year.

In Kyonggi-do, temperatures were $>15{ }^{\circ} \mathrm{C}$ from late May to early September. The soil moisture content was $>15 \mathrm{~mm}$ throughout the year. The maximum developmental stage was 4 from late May to early September. According to field observations (Lee et al. 2002), the observed population density of adult mosquitoes peaked in late June to late August.

In Kheda, water temperature decreased markedly in January. The soil moisture content increased from June to July, then decreased from September to November. Adult mosquitoes appeared June-November, and eggs emerged in January. According to field observations (Konradsen et al. (a) Yunnan
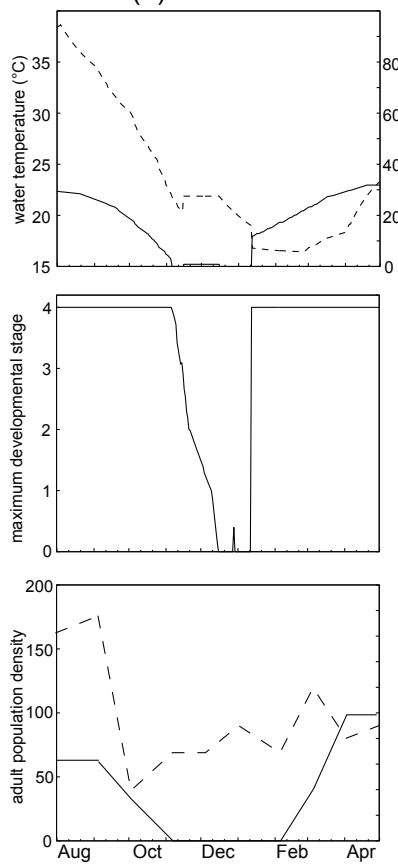

(b) Ishigaki
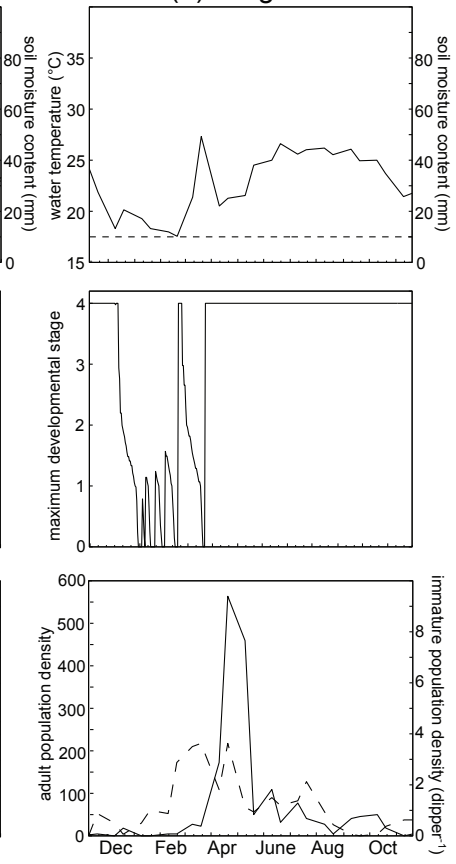

(c) Kyonggi-do
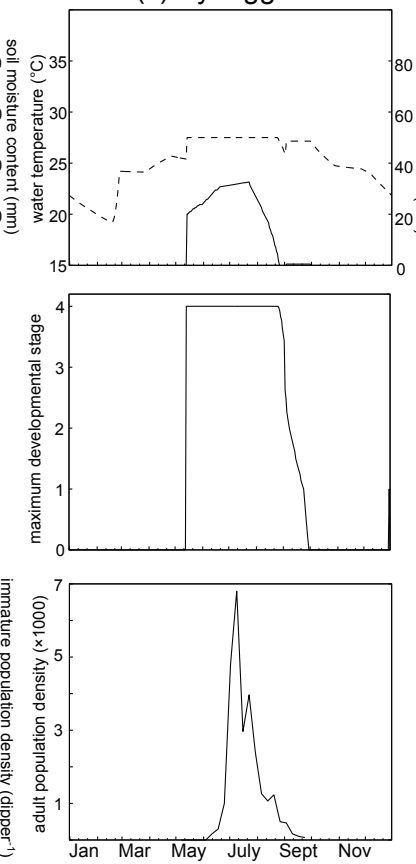

(d) Kheda
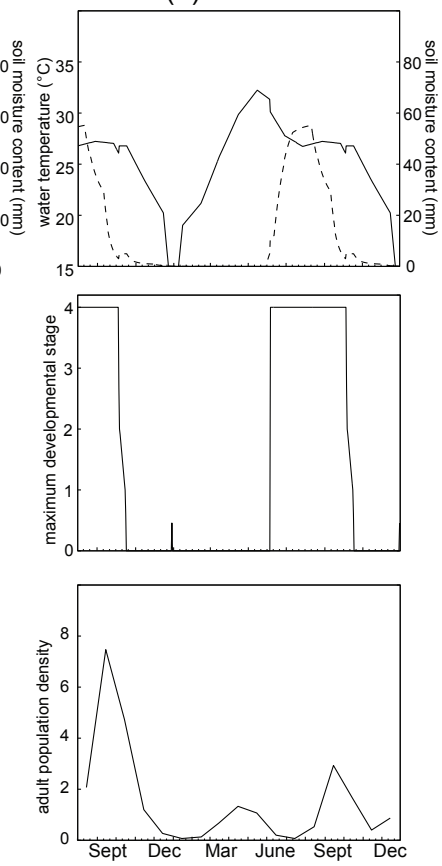

Fig. (5). Temporal variations in mosquito emergence and model output for representative sites: (a) Yunnan, China; (b) Ishigaki, Japan; (c) Kyonggi-do, South Korea; and (d) Kheda, India. The upper panels of (a)-(d) show variations in water temperature (solid line) and soil moisture content (dashed line) used in the growth model calculations. Water temperature $\left({ }^{\circ} \mathrm{C}\right)$ and soil moisture content $(\mathrm{mm})$ were calculated in the present study using the energy balance model and water budget method. The middle panels of (a)-(d) show the output of the model developed in this study. The lower panels show the adult population density (solid line) and immature population density (dashed line). The central panels show variations in the maximum developmental stage calculated using Eq. (3). The lower panels show the variations in observed population density from the references (Ono 1992, Konradsen et al. 1998, Lee et al. 2002, Toma et al. 2002). The solid lines indicate the adult population density and the dashed lines denote the immature population density. 
1998), adult mosquitoes emerged from September to November.

\section{Seasonal Changes in the Geographic Distribution}

To illustrate seasonal variations in the geographic distribution of adult occurrence, the maximum developmental stage of the mosquito was calculated using the same methods used for Fig. (5) (center panel). The occurrence of the mosquito is illustrated if the maximum developmental stage reached 3 (Fig. 1a). The results of the bimonthly calculations are illustrated in Fig. (6).

Mosquito emergence was limited seasonally in most areas (Fig. 6). Only in tropical regions such as Southeast Asia, particularly in Kalimantan and New Guinea, was the
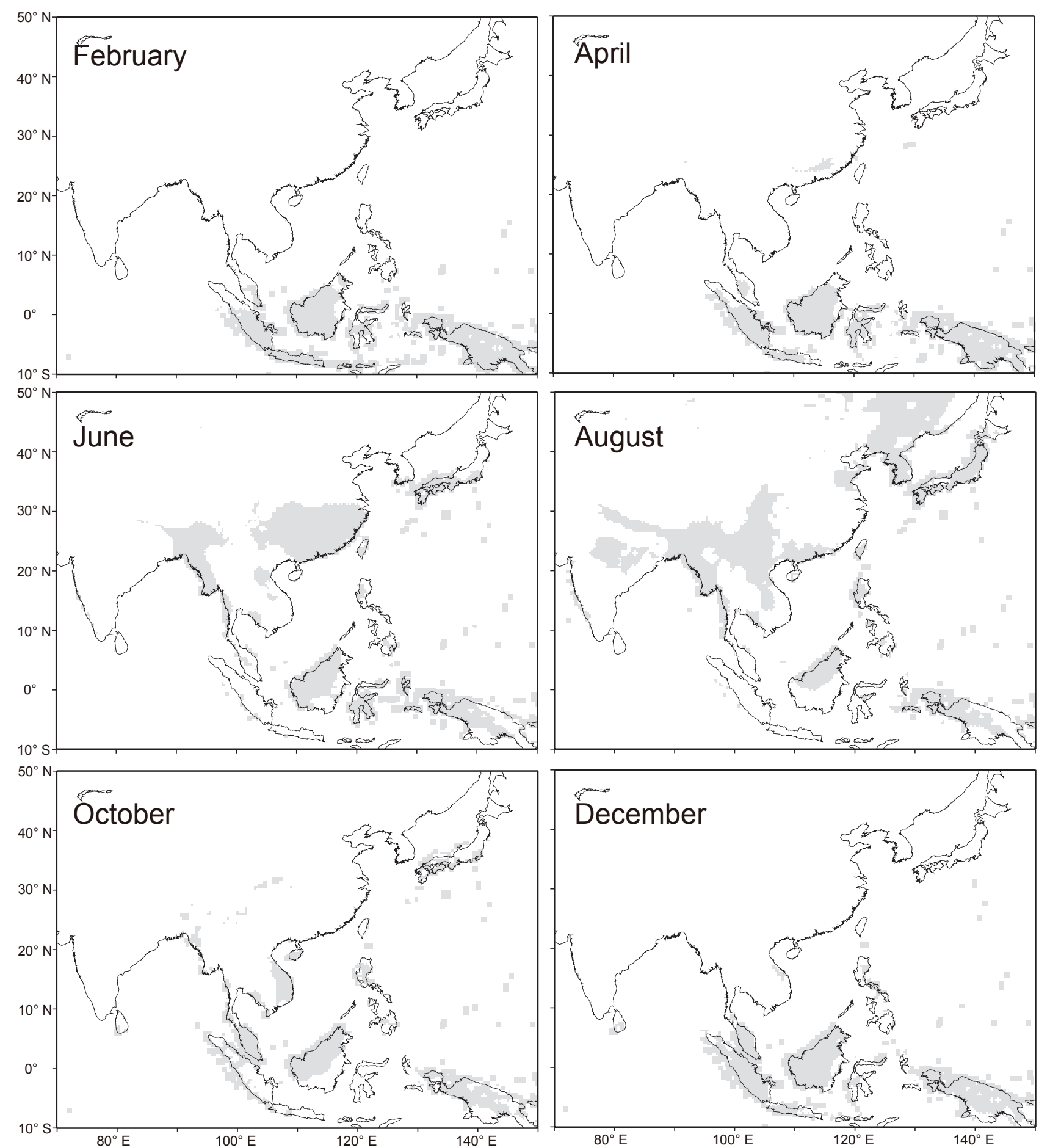

Fig. (6). Geographic distribution of bimonthly adult mosquito occurrence. Gray shading indicates the area in which the maximum development reached the adult stage. 
Anopheles adult able to survive year-round. Adults were viable in Sumatra other than in June-August, which is a relatively dry season. On the other hand, in some areas of semi-arid tropical countries such as inland India or Thailand, the season in which the mosquito was able to appear was limited to June-October. In subtropical regions such as the southern part of China, conditions were suitable for adult mosquitoes in June-August. The appearance of adult mosquitoes in temperate regions such as Japan, South Korea, and northeastern China was limited to the warm and humid summer season.

\section{Geographic Distribution of Average Developmental Length}

The distribution of the duration of Anopheles mosquito development from egg hatching to adult emergence is illustrated in Fig. (7). The duration was counted from the day when the egg stage began to the day of adult emergence, corresponding to $C_{\text {total }}=3$, which represented actual adult emergence in the model. To exclude the cases where the mosquito did not develop into an adult, this calculation was performed only if the maximum developmental stage of the day was adult. The average developmental length $\left(D_{\text {average }}\right.$, day) was calculated as follows:

$D_{\text {average }}=\frac{\sum_{i=1}^{G_{\max }} D_{i}}{G_{\max }}$ where $D_{i}$ is the developmental length (day) of $i$ th generation from egg hatching to adult emergence, $i$ is the number of generations, and $G_{\max }$ is the maximum number of generations as described in Materials and Methods. The average developmental length indicates the duration of development from egg to adult emergence of the mosquito. Model estimations of $D_{\text {average }}$ obtained using Eq. (5) ranged from approximately $10 \mathrm{~d}$ to more than a month (Fig. 7). At lower latitudes, $D_{\text {average }}$ was shorter than at higher latitudes, except for eastern China (transect A in Fig. 3).

\section{Limiting Factors for the Temporal and Spatial Distributions}

The maximum number of generations $\left(G_{\max }\right)$ was calculated to evaluate the frequency of mosquito occurrence (Fig. 8). At latitudes below $10^{\circ} \mathrm{N}$, the maximum number of generations was $>12$, and decreased with increasing latitude, reflecting the availability of moisture and the water temperature conditions. The distribution patterns of the maximum number of generations (Fig. 8) differed from that of the average developmental length (Fig. 7) at latitudes above $10^{\circ} \mathrm{N}$. In inland India and Thailand, although the average developmental length were very low due to higher temperatures, the maximum number of generations was limited to 3-4, similar to temperate climates.

Fig. (9) shows the relationship between the developmental length and the maximum number of generations. If the period of favorable climatic conditions is the same length, the maximum number of generations $\left(G_{\max }\right)$ increases

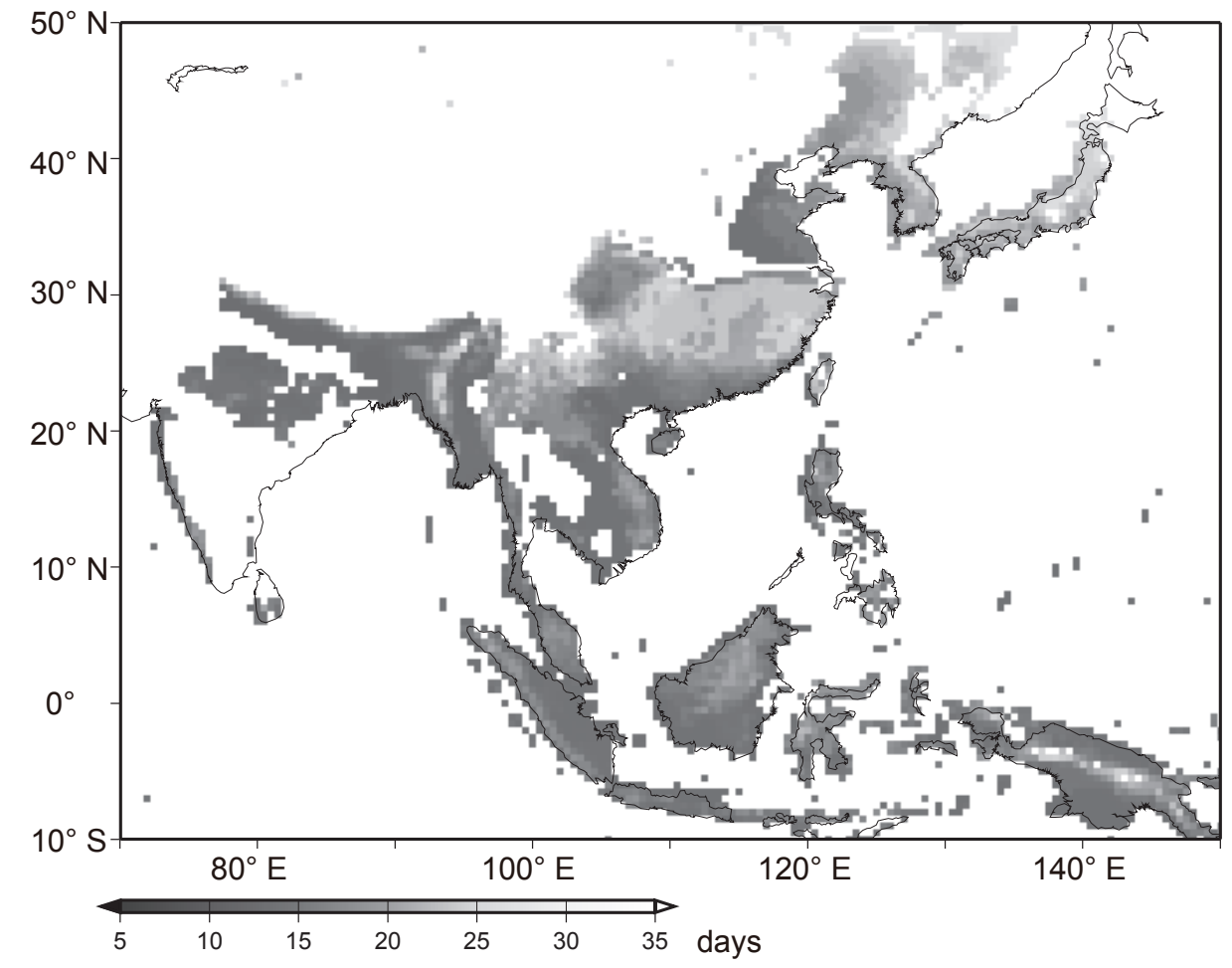

Fig. (7). Geographic distribution of average developmental length (days) of Anopheles mosquito development. Gray shading indicates the average developmental length $\left(D_{\text {average }}\right)$ of mosquitoes, calculated using Eq. (5). The area of $D_{\text {average }}=0$, where there was no occurrence of Anopheles, was described as white color. In most of the area, the standard deviation (SD) of the developmental length was less than 3 days. However, the SD of the developmental length in some areas of Japan and Southeastern China was 5-6 days. This could be due to variations in the temperature and moisture conditions during seasons when mosquito can survive. 


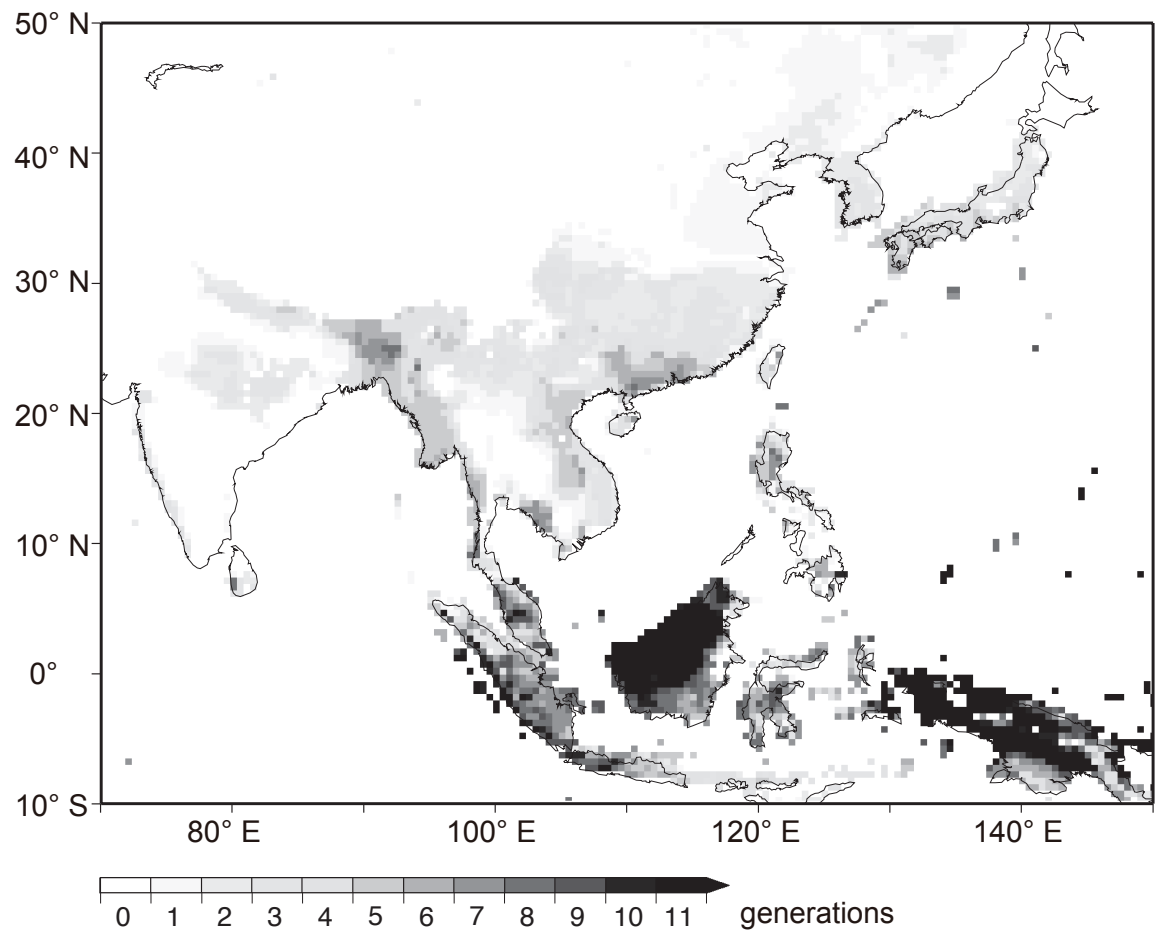

Fig. (8). Geographic distribution of the maximum number of generations.

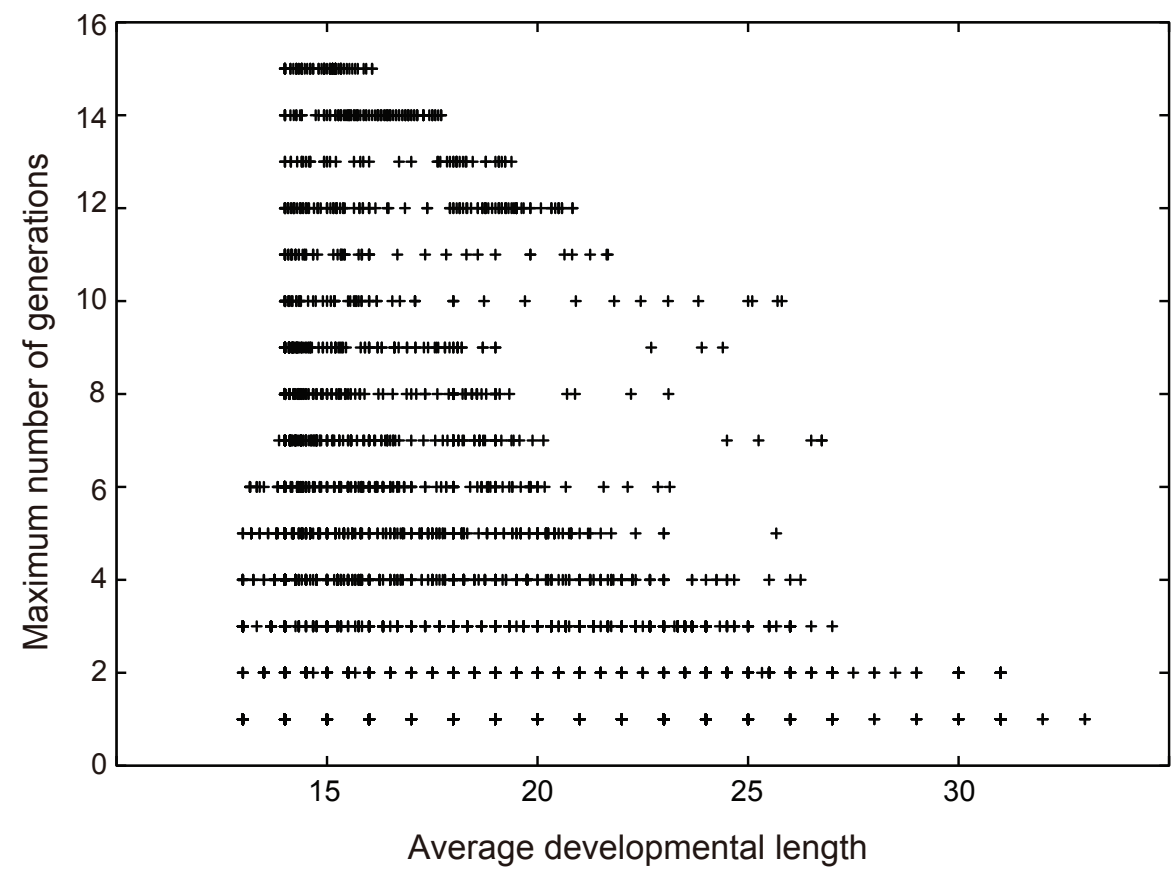

Fig. (9). Relationship between the average duration of Anopheles mosquito development and the maximum number of generations.

as the average developmental length $\left(D_{\text {average }}\right)$ decreases. However, some plots in Fig. (9) have low values for $G_{\max }$, despite low values for $D_{\text {average }}$. The relationship between average developmental length and the maximum number of generations is not well correlated $(R=-0.337)$.

\section{Latitudinal Variation in Climate Conditions}

The habitat of the mosquito was limited by soil moisture content and water temperature (Figs. 6 and 8). The duration of adult mosquito occurrence, optimal moisture conditions, and optimal temperatures for transects A, B, and C (Fig. 3) are shown in Fig. (10) to analyze the limiting factors for mosquito growth. In Fig. (10) (upper panel), the periods in which the maximum developmental stage was $>3$ are illustrated as vertical bars, indicating potential adult mosquito emergence. The center and lower panels of Fig. (10) show the duration of optimal moisture conditions and water temperatures for the mosquito, respectively. 


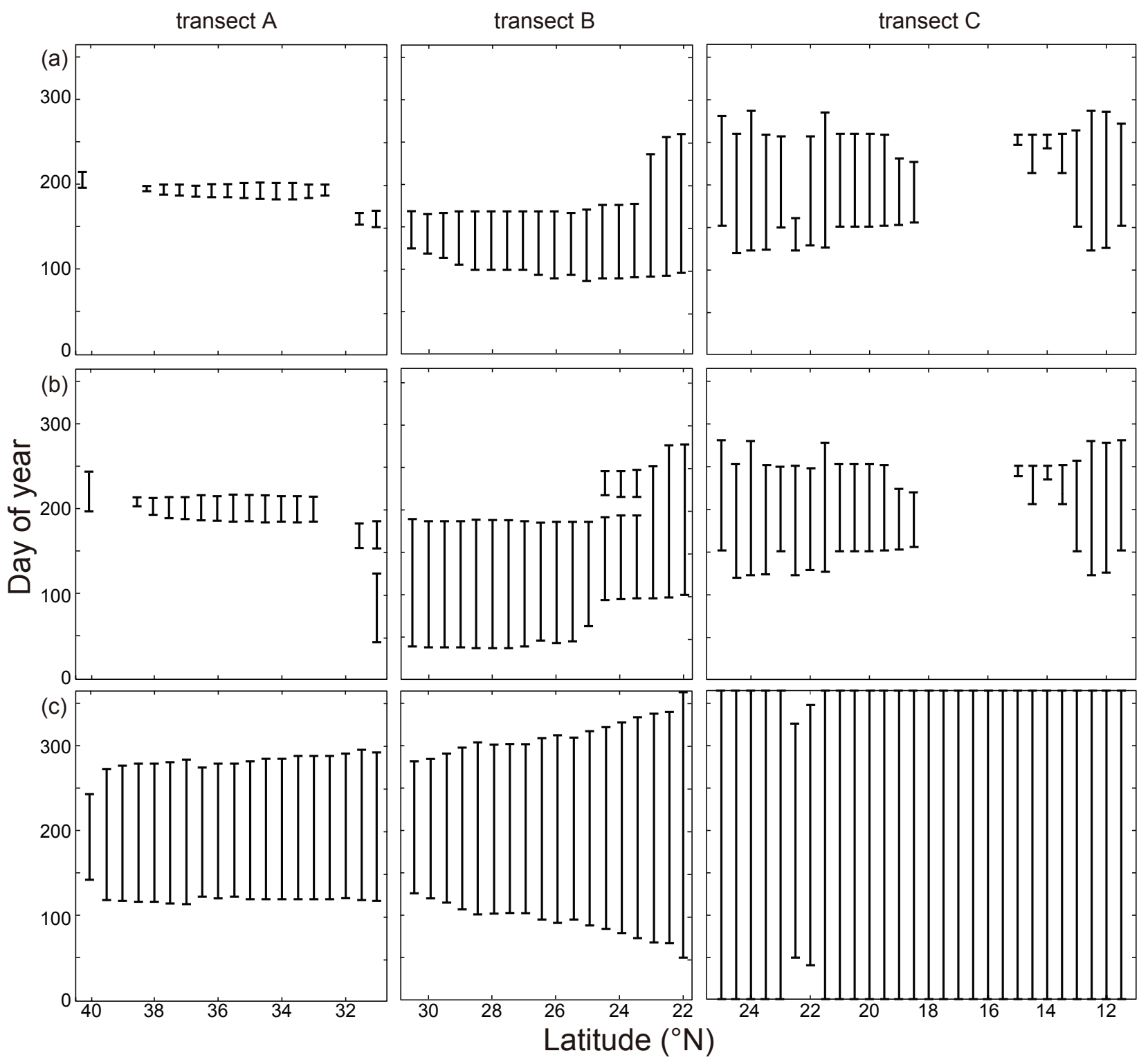

Fig. (10). Latitudinal variations in the occurrence of the Anopheles mosquito and its limiting factors along transects shown in Fig. (3): (a) periods of adult mosquito occurrence, (b) periods of optimal moisture conditions, (c) periods of optimal temperatures. The bottom of the bar indicates the start date of the period and the top of the bar indicates the end of the period.

The duration of the adult stage at latitudes above $33^{\circ} \mathrm{N}$ along transect $\mathrm{A}$ (corresponding to eastern China) was limited to $<50 \mathrm{~d}$, although the duration of optimal water temperatures was approximately $150-200 \mathrm{~d}$ in the same region. There were also gaps in the periods of optimal water temperature and optimal moisture content along transect B, corresponding to southeastern China. However, these gaps in the optimal conditions were not as wide as for transect A (middle and lower panels of transects $\mathbf{A}$ and $\mathbf{B}$ in Fig. 10). The longest period of adult emergence occurred at latitudes below $13^{\circ} \mathrm{N}$ and at $18-24^{\circ} \mathrm{N}$ along transect $\mathrm{C}$ in Cambodia and Bangladesh, where the durations of both the optimal temperature and optimal moisture conditions were longest. Although the water temperature was suitable for mosquito growth throughout the year along transect $\mathrm{C}$, the duration of the adult stage was limited due to a shortage of moisture from $16-18^{\circ} \mathrm{N}$, corresponding to northwestern Thailand.

\section{DISCUSSION}

\section{Characteristics of the Model for the Potential Distribution of Anopheles}

The results of the life history model (central panels in Fig. 5) for the temporal occurrence of the Anopheles mosquito coincided with the observations of occurrence at each intensive observation site, which represented various climates such as humid tropical, semi-arid, and temperate regions (lower panels in Fig. 5). The model was not able to simulate the temporal variations in mosquito occurrence (Fig. 4) as accurately as the results of Depinay et al. (2004), likely because they focused on a local site. Simulation of the seasonal changes in mosquito occurrence was sufficient to evaluate potential occurrence on a broad scale. The model accurately simulated the geographic distribution, and the distribution obtained from the model show trends similar to 
that of the mosquito observations (small closed circles in Fig. 3) and the results of Hopp \& Foley (2001), who simulated the geographic distribution of the Aedes mosquito. The niche-based (Foley et al. 2008, Medley 2010) and fuzzy logic (Craig et al. 1999) models based on calculations with a time-step of one year were able to show only annual average distributions for the mosquito. The present model is able to illustrate the seasonal changes in the geographic distribution of the mosquito by calculating mosquito growth with a timestep of one day (Fig. 6). The results obtained from the model are not actual but potential distribution of the Anopheles mosquito.

\section{Remarks on the Temporal and Spatial Distributions of Anopheles in Asia}

This method was developed to express the temporal and spatial distributions of the Anopheles mosquito in Asia. There are three main conclusions that can be drawn from the results.

First, the distribution and the duration of appearance of the Anopheles mosquito were limited by soil moisture content rather than water temperatures (Figs. 9 and 10). The lack of correlation between the average developmental length and the maximum number of generations shown in Fig. (9) indicates that the duration of Anopheles appearance is limited by insufficient moisture conditions. It is seldom that both optimal water temperature and soil moisture conditions exist simultaneously in many areas of inland Asia, such as eastern China and northwestern Thailand (Fig. 10). Although the developmental length of the Anopheles mosquito in Eastern China (transect A) is relatively short compared to that at the same latitudes (Fig. 7), the growing period is severely limited to approximately $50 \mathrm{~d}$ due to reduced soil moisture content (Fig. 10).

Second, the geographic distribution of the Anopheles mosquito based on our results (Figs. 6 and 8) differs from that of malaria transmission (WHO 1989, Jetten \& Takken 1994, Martens et al. 1999). It is possible for temperate regions such as the southernmost part of Japan to have mosquitoes in the summer, as these regions are within the potential climatological distribution area of the Anopheles mosquito, although malaria has been completely eradicated. The maximum number of generations is not large enough to support malaria transmission in temperate regions (Fig. 8).

Third, the model results indicated that the duration of mosquito emergence and distribution is climatically limited to a few rainy months in semi-arid areas, such as inland India, where the malaria incidence is very high at the present time (Figs. 6 and 8). The malaria incidence in India has been reported throughout the country (WHO 2008) and the model results for this area underestimated the current distribution. This may be caused by the lack of developmental rate data for the species that are found in India (Fig. 2). Similar variance in the climatologically based distribution of the vector mosquito and actual distribution was also reported by Hopp \& Foley (2001), and the study noted that people living in dry regions tend to store water in and around their homes, providing ample breeding grounds for this domestic species (Shope 1991). Furthermore, irrigation canal water or other agricultural water use has also been identified as a habitat for vector production in semi-arid areas (Konradsen et al. 1998). To estimate mosquito occurrence in such cases, the model should incorporate not only water movement in the vertical direction, such as precipitation and evapotranspiration, but also in the horizontal direction, such as human water use.

\section{Necessity for Experimental and Observational Data}

Although this study provides a framework for assessment of the Anopheles mosquito distribution in relation to climate factors, basic data on mosquito biology is limited. In particular, experimental data on the relationship between temperature and developmental rate of the mosquito is limited (Fig. 2); thus, it was necessary to include data for various Anopheles mosquito species of Asia and Africa. To simulate the mosquito population dynamics at local sites, data for each species are needed. Observations of the seasonal variations in the Anopheles population used to validate the model were limited to only eight sites. To better assess the transmission risk of malaria for a variety of cases, it is recommended that such data from a variety of field studies around the world be developed and shared (Hay et al. 2009).

\section{Application of the Model to Changing Climate Conditions}

Most studies that have assessed the impacts of climate change on the incidence and geographical range of malaria have assumed that the mosquito distribution would not change under future climate conditions (Martens et al. 1999, van Lieshout et al. 2004). The present model will contribute to evaluation of the effects of future climate change on malaria transmission through assessment of the potential future distribution of the Anopheles mosquito.

The present model, driven by simple climate data, is able to predict the basic distribution of the mosquito to assess the transmission risk of malaria and changes under climate change scenarios such as El Niño-Southern Oscillation (ENSO). ENSO events cause rainfall patterns to change, and this typically affects the habitat of immature stages of the vector mosquito. Rainfall in arid regions and drought in humid climates create pools that are suitable for mosquito development (Kovats et al. 2003). Although the relationship between ENSO and malaria incidence has been quantified (Kovats et al. 2003, Mabaso et al. 2007), analysis of this relationship focusing on vector mosquito occurrence has not been conducted. To elucidate the effects of ENSO on epidemic malaria, mosquito occurrence can be simulated using the model developed in this study.

\section{ACKNOWLEDGEMENTS}

This study was funded in part by the Ministry of Education, Science and Culture of Japan (Grant-in-Aid for Scientific Research C-21510022) and a Waseda University Grant for Special Research Projects (2008B-244). We also wish to thank Prof. Y. Morikawa, Prof. H. Koizumi, and Prof. S. Nishimura (Waseda University) for their useful comments on this study. 


\section{REFERENCES}

Allen, RG, Pereira, LS, Raes, D \& Smith, M (1998) Crop Evapotranspiration: Guidelines for Computing Crop Water Requirements. United Nations Food and Agriculture Organization, Irrigation and Drainage Rome, 300 Paper 56.

Bayoh, MN \& Lindsay SW (2003) Effect of temperature on the development of the aquatic stages of Anopheles gambiae sensu stricto (Diptera: Culicidae). Bulletin of Entomological Research, 93, 375-81.

Craig, MH, Snow, RW \& le Sueur, D (1999) A climate-based distribution model of malaria transmission in sub-Saharan Africa. Parasitology Today, 15, 105-11.

Chen, B, Harbach, RE \& Butlin, RK (2002) Molecular and morphological studies on the Anopheles minimus group of mosquitoes in southern China: taxonomic review, distribution and malaria vector status. Medical and Veterinary Entomology, 16, 253-65.

Chen, B, Butlin, RK, Pedro, PM, Wang, XZ \& Harbach, RE (2006) Molecular variation, systematics and distribution of the Anopheles fluviatilis complex in southern Asia. Medical and Veterinary Entomology, 20, 33-43.

Dev, V (1996) Anopheles minimus: its bionomics and role in the transmission of malaria in Assam, India. Bulletin of the World Health Organization, 74, 61-6.

Depinay, JMO, Mbogo, CM, Killeen, G, Knols, B, Beier, J, Carlson, J, Dushoff, J, Billingsley, P, Mwambi, H, Githure, J, Toure, AM \& McKenzie, FE (2004) A simulation model of African Anopheles ecology and population dynamics for the analysis of malaria transmission. Malaria Journal, 3, 29.

Dunne, KA \& Willmott, CJ (1996) Global distribution of plant-extractable water capacity of soil. International Journal of Climatology, 16, $841-59$.

Foley, DH, Rueda, LM, Peterson, AT \& Wilkerson, RC (2008) Potential distribution of two species in the medically important Anopheles minimus complex (Diptera: Culicidae). Journal of Medical Entomology, 45, 852-60.

Hay, SI, Guerra, CA, Gething, PW, Patil, AP, Tatem, AJ, Noor, AM, Kabaria, CW, Manh, BH, Elyazar, IRF, Brooker, S, Smith, DL, Moyeed, RA, \& Snow, RW (2009) A world malaria map: Plasmodium falciparum endemicity in 2007. PLoS Medicine, 6, 0286-302.

Hopp, MJ \& Foley, JA (2001) Global-scale relationships between climate and the dengue fever vector, Aedes aegypti. Climatic Change, 48, 441-63.

Hu, XM, Tsuda, Y \& Takagi, M (2003) Survival and development of larvae of three tropical malaria vectors (Diptera: Culicidae) under a seasonally changing temperature condition in Nagasaki, Japan. Medical Entomology and Zoology, 54, 371-79.

Jetten, TH \& Takken, W (1994) Anophelism without malaria in Europe: a review of the ecology and distribution of the genus Anopheles in Europe. Wageningen Agricultural University Press: Wageningen. $69 \mathrm{p}$.

Kiritani, K (2006) Predicting impacts of global warming on population dynamics and distribution of arthropods in Japan. Population Ecology, 48, 5-12

Konradsen, F, Stobberup, KA, Sharma, SK, Gulati, OT \& van der Hoek, W (1998) Irrigation water releases and Anopheles culicifacies abundance in Gujarat, India. Acta Tropica, 71, 195-97.

Kovats, RS, Bouma, MJ, Hajat, S, Worrall, E \& Haines, A (2003) El Niño and health. The Lancet, 362, 1481-89.

Lardeux, FJ, Tejerina, RH, Quispe, V \& Chavez, TK (2008) A physiological time analysis of the duration of the gonotrophic cycle of Anopheles pseudopunctipennis and its implications for malaria transmission in Bolivia. Malaria Journal, 7, 141
Lee, JS, Lee, WJ, Cho, SH, \& Ree, HI (2002) Outbreak of vivax malaria in areas adjacent to the demilitarized zone, South Korea, 1998. American Journal of Tropical Medicine and Hygiene, 66, 13-17.

Mabaso, MLH, Kleinschmidt, I, Sharp, B \& Smith, T (2007) El Niño Southern Oscillation (ENSO) and annual malaria incidence in Southern Africa. Transactions of the Royal Society of Tropical Medicine and Hygiene, 101, 326-30.

Martens, P, Kovats, RS, Nijhof, S, de Vries, P, Livermore, MTJ, Bradley, DJ, Cox, J \& McMichael, AJ (1999) Climate change and future populations at risk of malaria. Global Environmental Change, 9, S89-S107.

Medley, KA (2010) Niche shifts during the global invasion of the Asian tiger mosquito, Aedes albopictus skuse (Culicidae), revealed by reciprocal distribution models. Global Ecology and Biogeography, $19,122-33$

Mogi, M \& Okazawa, T (1996) Development of Anopheles sinensis immatures (Diptera: Culicidae) in the field: effects of temperature and nutrition. Medical Entomology and Zoology, 47, 355-62.

New, M, Hulme, M \& Jones, P (1999) Representing twentieth-century space-time climate variability. Part 1: development of a 1961-90 mean monthly terrestrial climatology. Journal of Climate, 12, 82956.

Ohta, S, Uchijima, Z, Seino, H \& Oshima, Y (1993) Probable effects of $\mathrm{CO}_{2}$-induced climatic warming on the thermal environment of ponded shallow water. Climatic Change, 23, 69-90.

Ohta, S \& Kimura, A (2007) Impacts of climate changes on the temperature of paddy waters and suitable land for rice cultivation in Japan. Agricultural and Forest Meteorology, 147, 186-98.

Ono, M (1992) Study on the effects of global warming on vector-born diseases. Global Environment Research Fund, B-13, Tokyo (in Japanese), pp. 342-51.

Overgaard, HJ, Tsuda, Y, Suwonkerd, W \& Takagi, M (2002) Characteristics of Anopheles minimus (Diptera: Culicidae) larval habitats in northern Thailand. Environmental Entomology, 31, 13441.

Rueda, LM, Kim, HC, Klein, TA, Pecor, JE., Li, C, Sithiprasasna, R, Debboun, M \& Wilkerson, RC (2006) Distribution and larval habitat characteristics of Anopheles hyrcanus group and related mosquito species (Diptera: Culicidae) in South Korea. Journal of Vector Ecology, 31, 198-205.

Shope, R (1991) Global climate change and infectious diseases. Environmental Health Perspectives, 96, 171-74.

Singh, OP, Chandra, D, Nanda, N, Raghavendra, K, Sunil, S, Sharma, SK, Dua, VK \& Subbarao, SK (2004) Differentiation of members of the Anopheles fluviatilis species complex by an allele-specific polymerase chain reaction based on $28 \mathrm{~S}$ ribosomal DNA sequences. American Journal of Tropical Medicine and Hygiene, 70, 27-32.

Tao, F, Yokozawa, M, Hayashi, Y \& Lin, E (2003) Future climate change, the agricultural water cycle, and agricultural production in China Agriculture, Ecosystems \& Environment, 95, 203-15.

Toma, T, Miyagi, I, Malenganisho, WLM, Murakami, H, Nerome, H \& Yonamine, M (2002) Distribution and seasonal occurrence of Anopheles minimus in Ishigaki Island, Ryukyu Archipelago, Japan, 1998-1999. Medical Entomology and Zoology, 53, 29-42.

van Lieshout, M, Kovats, RS, Livermore, MTJ \& Martens, P (2004) Climate change and malaria: analysis of the SRES climate and socioeconomic scenarios. Global Environmental Change, 14, 87-99.

World Health Organization (1989) Geographical distribution of arthropodborne diseases and their principal vectors. WHO, Geneva 134.

World Health Organization (2008) World Malaria Report 2008. WHO, Geneva 190

Yeom, JS, Ryu, SH, Oh, S, Lee, WJ, Kim, TS, Kim, KH, Kim, YA, Ahn, SY, Cha, JE \& Park, JW (2005) Status of Plasmodium vivax malaria in the Republic of Korea during 2001-2003. American Journal of Tropical Medicine and Hygiene, 73, 604-8.

(C) Kashiwada and Ohta; Licensee Bentham Open.

This is an open access article licensed under the terms of the Creative Commons Attribution Non-Commercial License (http://creativecommons.org/licenses/bync/3.0/), which permits unrestricted, non-commercial use, distribution \& reproduction in any medium, provided the work is properly cited. 